\title{
LETTER
}

\section{Movements after the clinical diagnosis of brain death: supraspinal motor responses or spinal reflexes}

\author{
Mohamed Y Rady ${ }^{1 *}$ and Joseph L Verheijde ${ }^{2}$ \\ See related research by Wu and Orizaola Balaguer, http://ccforum.com/content/17/4/440
}

In a recent issue of Critical Care, Wu and Orizaola Balaguer [1] hypothesized that nociceptive head turning after brain death (BD) is a spinal reflex. We argue that it can be a supraspinal response, which would invalidate a diagnosis of $\mathrm{BD}$.

The sternocleidomastoid and trapezius are innervated by the spinal nucleus of the accessory nerve extending from the lower medulla to the ventral horn of the spinal cord (C1-C4) [2]. Lower motor neurons from the lower medulla to $\mathrm{C} 2$ project to the sternocleidomastoid [2], contributing to the reported motor responses.

The spinal nerve roots of the accessory nerve ascend through the foramen magnum and descend through the jugular foramen. Compression of the vertebral-basilar arteries (causing intracranial circulatory arrest) and the spinal nerve roots by cerebellar tonsillar herniation at the foramen magnum would abolish the spinal accessory nerve reflex as well as cause cervicomedullary infarction.
The pyramidal tract projecting from the telencephalon controls voluntary movements. Subcortical nuclei in the diencephalon, mesencephalon, and rhombencephalon control non-voluntary movements. Complex movements are generally explained as spinal reflexes rather than supraspinal motor responses, despite an incidence of $40 \%$ to $50 \%$ in heart-beating donors [3]. Dismissal of supraspinal motor responses is incongruent with the finding [4] that, on histopathological examination, about $60 \%$ of heart-beating donors have normal or minimal ischemic injury to the brainstem. If (as these histopathological findings show) the subcortical nuclei are possibly uninjured, then the supraspinal origin of movements cannot be excluded [5].

The absence of brainstem injury at autopsy raises doubt that all movements in BD are spinal motor reflexes. Additional histopathological data are needed to determine whether movements originate from supraspinal or spinal nuclei.

\section{Authors' response \\ Yunfen Wu and Pedro Orizaola Balaguer}

We appreciate the comments from Rady and Verheijde in response to our reported case. However, we do not agree with their invalidation of the $\mathrm{BD}$ diagnosis in our patient. Our arguments are the following: first, the criteria for a clinical diagnosis of BD were fulfilled [6]; second, the electroencephalographic recording was isoelectric; and

\footnotetext{
*Correspondence: rady.mohamed@mayo.edu

'Department of Critical Care Medicine, Mayo Clinic, 5777 East Mayo Boulevard, Phoenix, AZ 85054, USA

Full list of author information is available at the end of the article
}

third, computed tomography angiography (CTA) showed signals of intracranial circulatory arrest (Figure 1). The sensitivity of CTA in detecting intracranial circulatory arrest has been shown to be comparable to that of other established techniques [7].

Nevertheless, we agree with Rady and Verheijde that a supraspinal origin of head-turning movements in our patient cannot be ruled out. In regard to the involved source of such movements in BD, we suggested in our previous report that further studies (including hispatological examination) are needed for this to be clarified. 


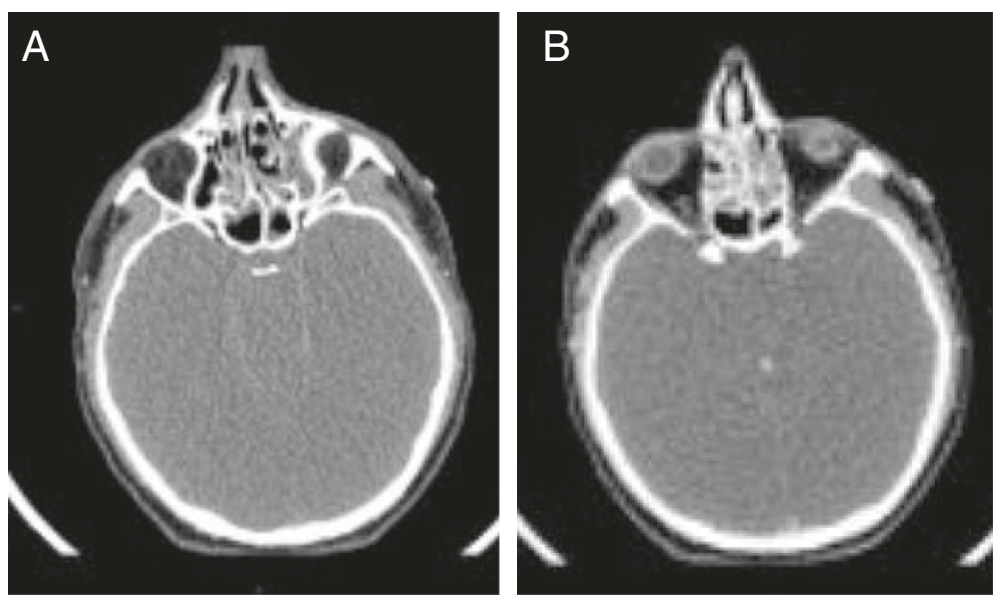

Figure 1 Computed tomography angiography (CTA) shows signals of intracranial circulatory arrest. (A) Axial-view CTA image of the arterial phase. Severe brain edema is shown. Both superficial temporal arteries are visualized. (B) Axial-view CTA image of the venous phase. In both frames, there is no enhancement of the middle cerebral arteries or the basilar artery.

\section{Abbreviations}

BD: Brain death; CTA: Computed tomography angiography.

\section{Competing interests}

The authors declare that they have no competing interests.

\section{Acknowledgements}

YW and POB thank the Radiology Department of Hospital Universitario de Marqués de Valdecilla for technical and analytical support with the CTA images. Written consent to publish was obtained from the patient's next of kin.

\section{Author details}

'Department of Critical Care Medicine, Mayo Clinic, 5777 East Mayo Boulevard, Phoenix, AZ 85054, USA. ${ }^{2}$ Departments of Physical Medicine and Rehabilitation, Mayo Clinic, 5777 East Mayo Boulevard, Phoenix, AZ 85054, USA.

Published: 18 November 2013

\section{References}

1. Wu Y, Orizaola Balaguer P: Spontaneous and reflex head turning in brain death. Crit Care 2013, 17:440

2. Routal RV, Pal GP: Location of the spinal nucleus of the accessory nerve in the human spinal cord. J Anat 2000, 196:263-268.

3. Saposnik G, Basile VS, Young GB: Movements in brain death: a systematic review. Can J Neurol Sci 2009, 36:154-160.

4. Wijdicks EF, Pfeifer EA: Neuropathology of brain death in the modern transplant era. Neurology 2008, 70:1234-1237.

5. Joffe AR, Anton NR: Some questions about brain death: a case report. Pediatr Neurol 2007, 37:289-291.

6. Practice parameters for determining brain death in adults (summary statement): the quality standards subcommittee of the American academy of neurology. Neurology 1995, 45:1012-1014.

7. Welschehold S, Kerz T, Boor S, Reuland K, Thömke F, Reuland A, Beyer C, Wagner W, Müller-Forell W, Giese A: Detection of intracranial circulatory arrest in brain death using cranial CT-angiography. Eur J Neurol 2013, 20:173-179.

doi:10.1186/cc13117

Cite this article as: Rady and Verheijde: Movements after the clinical diagnosis of brain death: supraspinal motor responses or spinal reflexes. Critical Care 2013 17:469. 